\title{
Morphological and ecological evidence for two sympatric forms of Type B killer whale around the Antarctic Peninsula
}

\author{
J. W. Durban ${ }^{1,2} \cdot$ H. Fearnbach ${ }^{1,2}$ • D. G. Burrows ${ }^{3}$ G. M. Ylitalo ${ }^{3}$ • \\ R. L. Pitman ${ }^{4}$
}

Received: 27 November 2015/Revised: 29 March 2016/ Accepted: 31 March 2016/Published online: 9 April 2016

(c) The Author(s) 2016. This article is published with open access at Springerlink.com

\begin{abstract}
Killer whales (Orcinus orca) are apex marine predators in Antarctica, but uncertainty over their taxonomic and ecological diversity constrains evaluations of their trophic interactions. We describe two distinct, sympatric forms sharing the characteristic pigmentation of Type B, the most common around the Antarctic Peninsula. Laser photogrammetry revealed nonoverlapping size differences among adults: Based on a body length index (BLI: blowhole to dorsal fin) adult females of the larger form ("B1") were $20 \%$ longer than the smaller form ("B2"), and adult males were $24 \%$ longer on average. Dorsal fins of B1 adult females were $19 \%$ taller than B2 females, and adult males $32 \%$ taller. Both types were strongly sexually dimorphic, but B1 more so, including for BLI (B1 males $=1.07 \times$ females; $\mathrm{B} 2=1.05 \times)$ and especially for dorsal fin height (B1 male fins $=2.33 \times$ female; $\mathrm{B} 2=2.10 \times)$. The characteristically large Type $\mathrm{B}$ eye patch was more extensive for B1 than B2, comprising 41
\end{abstract}

J. W. Durban

john.durban@noaa.gov

1 Center for Whale Research, 355 Smugglers Cove Rd., Friday Harbor, WA 98250, USA

2 Marine Mammal and Turtle Division, National Marine Fisheries Service, Southwest Fisheries Science Center, National Oceanic and Atmospheric Administration, $8901 \mathrm{La}$ Jolla Shores Dr., La Jolla, CA 92037, USA

3 National Marine Fisheries Service, Northwest Fisheries Science Center, National Oceanic and Atmospheric Administration, 2725 Montlake Boulevard East, Seattle, WA 98112, USA

4 Antarctic Ecosystem Research Division, National Marine Fisheries Service, Southwest Fisheries Science Center, National Oceanic and Atmospheric Administration, $8901 \mathrm{La}$ Jolla Shores Dr., La Jolla, CA 92037, USA and $37 \%$ of BLI, respectively. Average group size was also significantly different, with B1s in smaller groups (mean 7, range 1-14) and B2s more gregarious (mean 36, range 8-75). Stable isotope analysis of skin biopsies indicated dietary differences: a significantly lower nitrogen ${ }^{15} \mathrm{~N} /{ }^{14} \mathrm{~N}$ ratio in B2s supported observations of feeding primarily on krill consumers (e.g., pygoscelid penguins), while B1s prey mainly on predators of krill consumers (e.g., Weddell seals Leptonychotes weddellii). These differences likely represent adaptations to distinct foraging niches, which has led to genetic divergence; their ecology now needs further study.

Keywords Predator - Cetacean - Diet - Stable isotopes · Photogrammetry

\section{Introduction}

There is increasing recognition of the importance of topdown forcing within Antarctic marine ecosystems (Ainley et al. 2007, 2010). Killer whales (Orcinus orca) are abundant within these systems (Branch and Butterworth 2001), most notably around the Antarctic Peninsula (Pitman and Ensor 2003). However, a great deal of uncertainty remains over the extent of their taxonomic and ecological diversity (Pitman et al. 2007), constraining an evaluation of key trophic interactions involving these apex predators. Type B killer whales are one of four currently recognized morphotypes of killer whale in Antarctic waters and are the most common type found around the Antarctic Peninsula (Pitman and Ensor 2003; Pitman et al. 2011). They are readily distinguished from the other types by a dark dorsal cape and lighter lateral fields, and a noticeably large postocular eye patch (Pitman and Ensor 2003). Recent analysis 
of mitogenomics has indicated that Type $\mathrm{B}$ is divergent from other Antarctic killer whales and may represent a distinct species (Morin et al. 2010).

Despite a superficial similarity, recent field observations have suggested the existence of two sympatric forms in the coastal waters of the Antarctic Peninsula, both sharing characteristics of the Type B pigmentation pattern (Pitman 2011). An ostensibly larger form has been observed to feed mainly on ice seals (Pitman and Durban 2012), and a smaller form has to date been observed feeding only on pygoscelid penguins (Pitman and Durban 2010), but may also feed on fish (Pitman 2011). Here we present data to support morphological and ecological separation of these two forms, suggesting adaptation to distinct foraging niches. This represents important information for evaluating and predicting the trophic interactions of killer whales in this rapidly changing environment (Stammerjohn et al. 2008).

\section{Materials and methods}

Between 2009 and 2013, photogrammetry data and skin biopsies were collected from 24 groups of killer whales in coastal waters off the west side of the Antarctic Peninsula (Fig. 1), which we identified in the field as larger ("B1", $n=9$ groups) and smaller ("B2", $n=15$ groups) forms (Fig. 2). Photographs were taken from a $19.5 \mathrm{~m}$ motorsailing yacht or from small (4-5 m) launches, and measurement scale was obtained using the laser-metric approach (Durban and Parsons 2006). Two green laser pointers were held in a bracket on the tripod mount of a Nikon 80-200 mm f2.8 zoom lens, attached to a Nikon Digital SLR camera (D200 and D300s). The laser pointers were mounted and calibrated in a parallel orientation to project dots onto the whales' dorsal fins at a fixed separation of $10 \mathrm{~cm}$ apart. These dots provided a scale of known size that was documented in the photographs; once the pixel dimension of the known distance between the parallel laser dots was measured, we extrapolated the width (W) and height $(\mathrm{H})$ of the dorsal fin to real size, and further images displaying the dimensioned fin of this individual could then in turn be used to estimate a body length index (BLI) - the straight-line distance between the blowhole and anterior insertion of the dorsal fin, when visible above the water (Fig. 3). We also measured the length of the eye patch along the longest axis, when visible, and represented this as a proportion of BLI.

Individual whales were distinguished in high-quality photographs by variability in the shape of the saddle patch pigmentation, the shape of the dorsal fin, and patterns of naturally acquired notches in the fin (e.g., Durban et al. 2010). Where repeated measures of fin dimensions were available for the same whale, we selected the tallest and widest as the best to minimize negative bias from parallax errors, if the fin was imaged from slightly above, and horizontal-axis errors, if the whale's body orientation was not completely parallel to the camera's focal plane (Durban and Parsons 2006). Similarly, for the BLI, we selected the longest measurement that would be more robust to negative
Fig. 1 Map of the Antarctic Peninsula region where laser photogrammetry images were collected between 2009 and 2013 from nine groups of apparently larger Type B1 killer whales (open circles) and 15 groups of smaller Type B2 killer whales (filled squares)

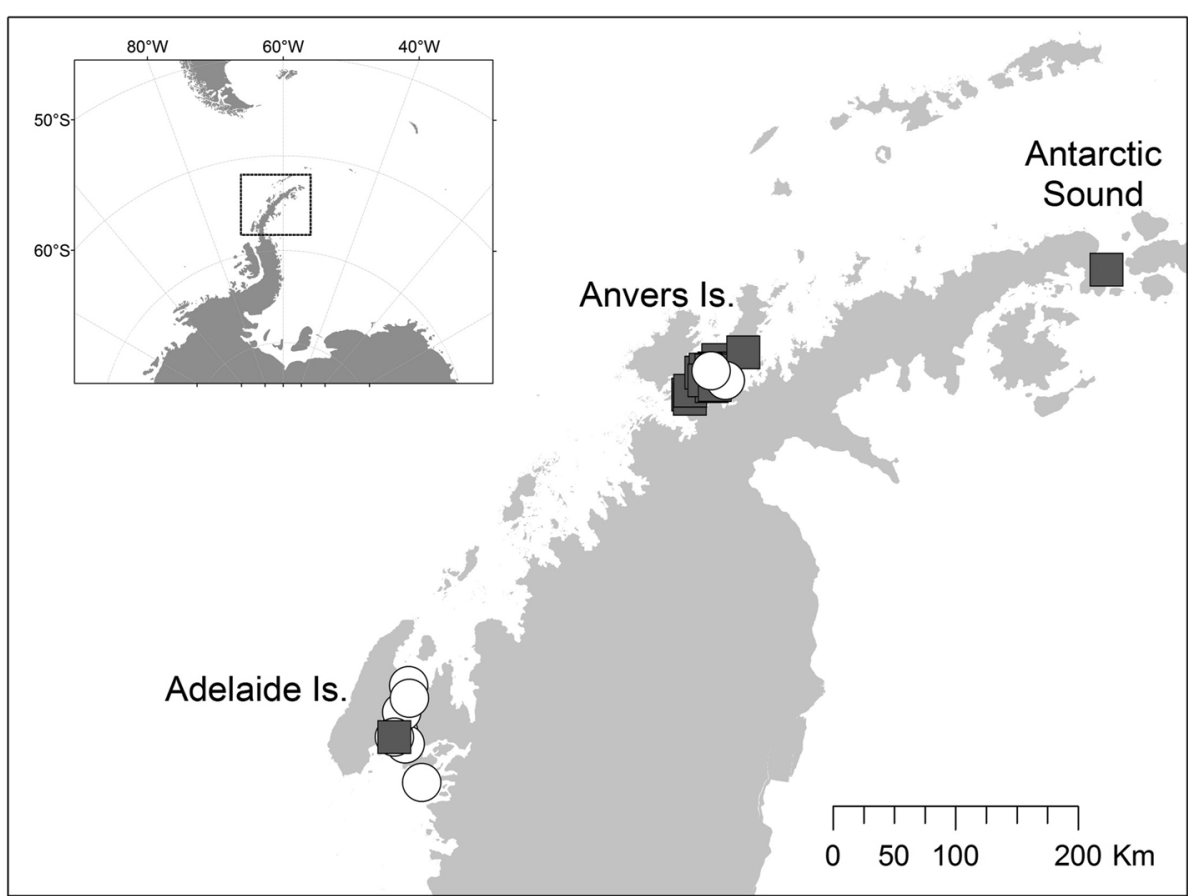


Fig. 2 Photographs of Type B1 killer whales (left) and B2 (right); top row shows adult males, and bottom row shows adult females, scaled to estimated whale sizes. Both types display the dorsal cape and large eye patch characteristic of Type B (Pitman and Ensor 2003)
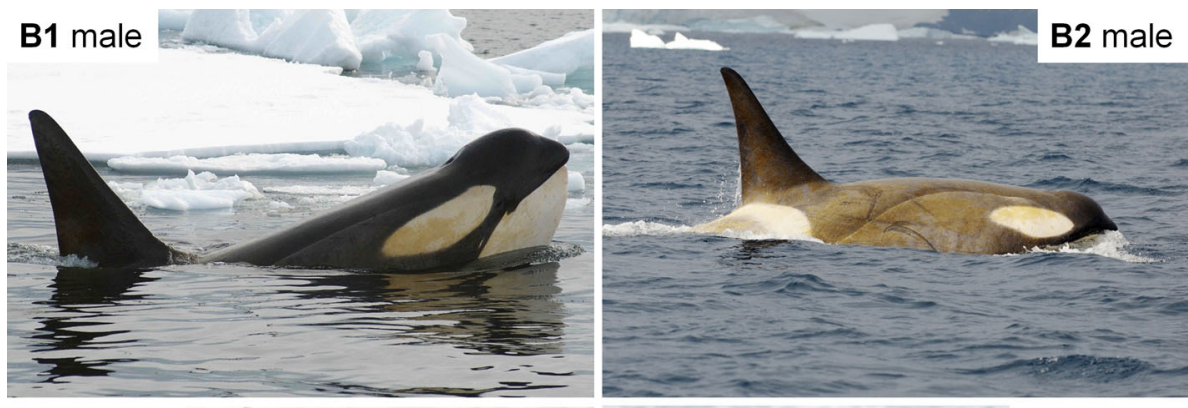

B1 female
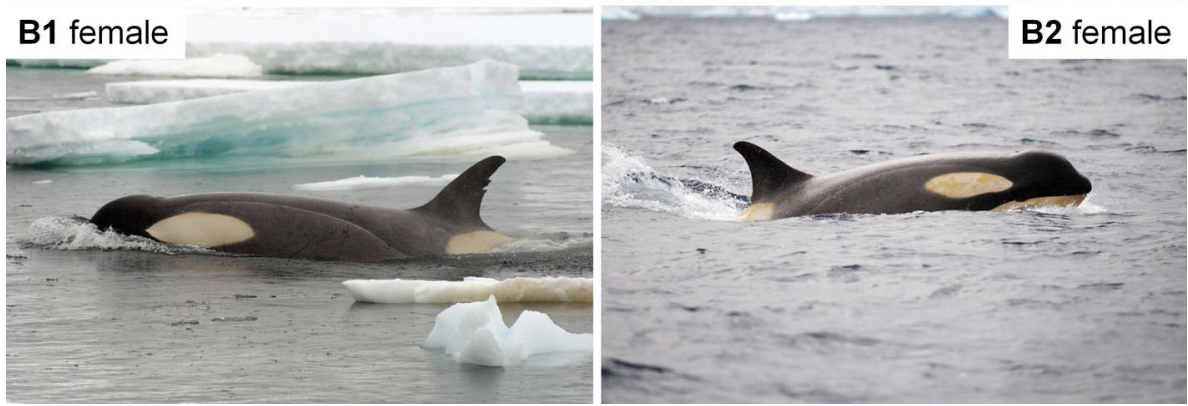

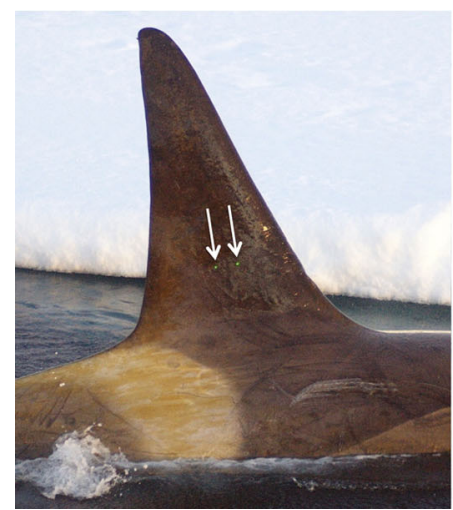

Fig. 3 Photographs of an adult male Type B1 killer whale with two green laser dots of $10 \mathrm{~cm}$ separation projected on the dorsal fin (indicated by arrows, left) and the extrapolation to derive the body length index (BLI, right). The lasers provide a scale of known size allowing the dimensions of the fin to be estimated (height,

bias from slightly off-perpendicular orientation or when the whale surfaced with a rounded back. For meaningful size comparisons, we restricted our analysis to individuals that were ostensibly of adult size and behavior, in comparison with smaller subadults and juveniles in the groups. Group size was estimated by consensus from a minimum of two visual observers counting whales that came within $500 \mathrm{~m}$ of each other and behaved in a coordinated fashion. These estimates were corroborated by minimum photo-identification counts of distinct individuals.

A crossbow (67 kg draw Barnett Wildcat) was used to project floating bolts with a $3.5-\mathrm{cm}$-long and $0.6-\mathrm{cm}$-diameter cutting tip (e.g., Hooker et al. 2001) to collect skin samples from the same groups for which photogrammetry
$H=145 \mathrm{~cm}$, width, $W=113 \mathrm{~cm}$; following Durban and Parsons 2006), and the fin can then be used in other photographs as a scale to estimate the straight-line distance from the anterior insertion of the dorsal fin to the center of the blowhole (Body Length Index, $\mathrm{BLI}=236 \mathrm{~cm})$

data were collected. Stable isotope analysis of epidermis from these biopsies was conducted on lipid-extracted tissue as described previously (e.g., Herman et al. 2005). Three replicate analyses of each skin sample were conducted, and stable isotope values of carbon and nitrogen were compared between $\mathrm{B} 1$ and $\mathrm{B} 2$ whales to examine ecological differences.

\section{Results and discussion}

Photogrammetry measurements were possible for 38 different adult whales, with a total of 134 images that showed clear laser dots on dorsal fins that were perpendicular to the 
camera and 138 images that showed the fin and body in perpendicular orientation. On average four (range 1-12) fin images and four (range 1-11) body images were collected from each whale. Of these individuals, 17 were confirmed to be adult females $\left(n_{\mathrm{B} 1}=5, n_{\mathrm{B} 2}=12\right)$ by the presence of accompanying calves surfacing in tight association (e.g., Pitman et al. 2007) and eight were identified as adult males ( $n_{\mathrm{B} 1}=4, n_{\mathrm{B} 2}=4$ ) based on the sexually dimorphic height of the dorsal fin (e.g., Durban and Parsons 2006). The distributions of BLI were discrete between whales identified as B1 or B2 forms in the field (Fig. 4), with all B1 whales longer than B2 whales. Confirmed adult females of the larger B1 type were significantly longer ( $t$ test, $p<0.0001)$ by $20 \%$ in BLI than B2 females on average [adult female $\mathrm{BLI}_{\mathrm{B} 1}$ mean $(x)=218 \mathrm{~cm}$, standard deviation $(\mathrm{SD})=8 \mathrm{~cm}$; adult female $\mathrm{BLI}_{\mathrm{B} 2} x=181 \mathrm{~cm}$, $\mathrm{SD}=9 \mathrm{~cm}]$, and B1 adult males were significantly longer ( $t$ test $p<0.0001$ ) by $24 \%$ than B2 males (adult male $\mathrm{BLI}_{\mathrm{B} 1} x=235 \mathrm{~cm}, \mathrm{SD}=4 \mathrm{~cm}$; adult male $\mathrm{BLI}_{\mathrm{B} 2}$ $x=190 \mathrm{~cm}, \mathrm{SD}=7 \mathrm{~cm}$; Fig. 4). Similarly, the dorsal fins of B1 adult females were significantly taller than B2 females ( $t$ test, $p=0.001$ ) by $19 \%$, in proportion to BLI differences (adult female $\mathrm{H}_{\mathrm{B} 1} x=56 \mathrm{~cm}, \mathrm{SD}=4 \mathrm{~cm}$; adult female $\left.\mathrm{H}_{\mathrm{B} 2} x=47 \mathrm{~cm}, \mathrm{SD}=4 \mathrm{~cm}\right)$. However, $\mathrm{B} 1$ adult males had significantly taller ( $t$ test, $p=0.0009$ ) dorsal fins by $32 \%$ than B2 males, in excess of BLI differences (adult male $\mathrm{H}_{\mathrm{B} 1} x=131 \mathrm{~cm}, \mathrm{SD}=9 \mathrm{~cm}$; adult male $\mathrm{H}_{\mathrm{B} 2} x=99 \mathrm{~cm}, \mathrm{SD}=6 \mathrm{~cm}$; Fig. 4). Both forms were significantly sexually dimorphic for BLI (adult male BLI $x=1.07$ times longer than female for B1, $t$ test $p=0.0006 ; 1.05$ times longer for $\mathrm{B} 2, t$ test $p=0.0461$ ) and most notably for dorsal fin height (adult male $\mathrm{H}$ $x=2.33$ times taller than adult female for B1 compared to $2.10 \times$ for $\mathrm{B} 2$; $t$ test $p<0.0001$ for both), but B1s had greater dimorphism than B2s, particularly in fin height.
In addition to size differences, these forms had subtle, but significant, pigmentation differences that facilitated their identification in the field. The characteristic large Type B eye patch was conspicuous on both forms, but was significantly more extensive for $\mathrm{B} 1$ than $\mathrm{B} 2$ ( $t$ test, $p=0.04)$, comprising $x=41 \%(n=8, \mathrm{SD}=4 \%)$ and $x=37 \%(n=11, \mathrm{SD}=3 \%)$ of the BLI, respectively (Fig. 2). These forms were also distinguished by typical group sizes, with B1 being encountered in significantly smaller groups $(x=7, \mathrm{SD}=4$, range $1-14)$ and $\mathrm{B} 2$ being more gregarious $(x=36, \mathrm{SD}=24$, range $8-75$; $t$ test, $p=0.0002$ ).

Stable isotope analysis of 19 skin samples $\left(n_{\mathrm{B} 1}=11\right.$, $\left.n_{\mathrm{B} 2}=8\right)$ further indicated key ecological differences between the two forms. Stable isotope values of both carbon and nitrogen showed significant differences between B1 and B2 whales (Fig. 5), but most notable were the difference in nitrogen isotope values, which are often used to assess the trophic level at which marine mammals feed (Krahn et al. 2007). Although the diet of the B1 whales appeared to be more variable than that of the B2 whales, as noted by the wider ranges of carbon and nitrogen stable isotope values, the average nitrogen isotope measures of individual B1 and B2 whales showed no overlap, supporting field observations of B2 whales feeding primarily on krill consumers (e.g., pygoscelid penguins, Pitman and Durban 2010; and probably fish, Pitman 2011), while B1s prey mainly on predators of krill consumers (e.g., Weddell seals Leptonychotes weddellii, Pitman and Durban 2012).

These results confirm our field observations of two distinct forms of Type B killer whale around the Antarctic Peninsula. Their morphological and ecological variability likely represents adaptation to distinct foraging niches, and over time might be expected to lead to genetic structuring.
Fig. 4 Histogram of body length indices (BLI) for Type $\mathrm{B} 1$ (open bars) and B2 (filled bars) killer whales; BLI is defined as the straight-line distance between the anterior insertion of the dorsal fin to the center of the blowhole, estimated using laser photogrammetry (see Fig. 2). Maximum BLI estimates per individual are shown for confirmed adult females (open symbols) and adult males (filled symbols) for each of Type B1 (circles) and B2 (squares)

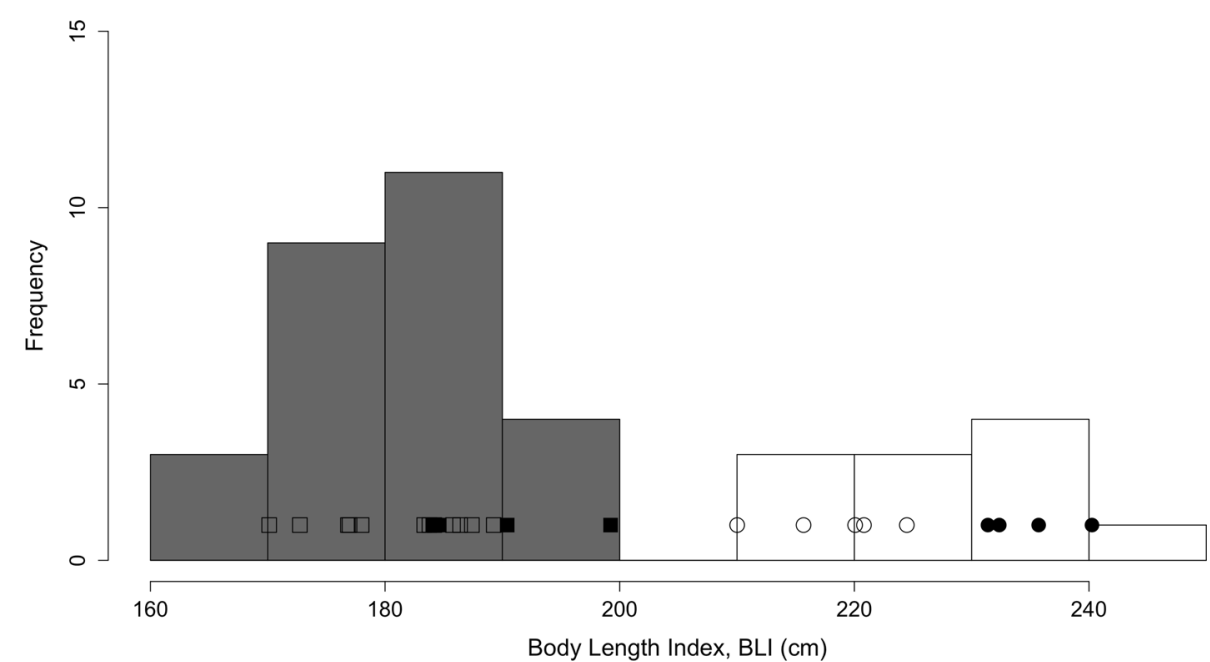




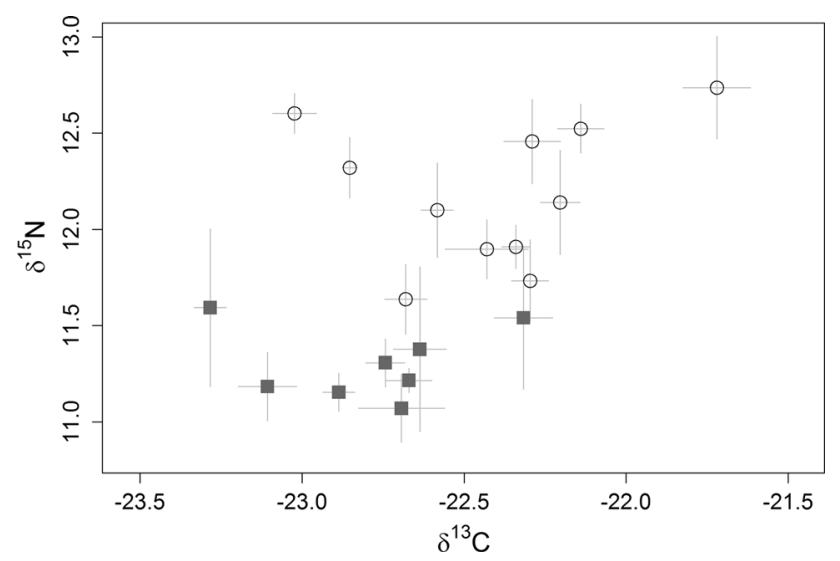

Fig. 5 Mean carbon and nitrogen stable isotope values in skin biopsies taken from the same groups of killer whales (Fig. 1) for which photogrammetry distinguished a larger Type (B1, open circles) and smaller Type (B2, filled squares). Error bars represent \pm 1 standard deviation (SD) of three analyses of each skin sample. Isotope values are expressed in $\delta$ notation as part per million. ${ }^{15} \mathrm{~N}$ and ${ }^{15} \mathrm{C}$ is the ratio of isotopes ${ }^{15} \mathrm{~N} /{ }^{14} \mathrm{~N}$ or ${ }^{13} \mathrm{C} /{ }^{12} \mathrm{C}$ for each tissue sample. The mean $(x){ }^{13} \mathrm{C}$ and ${ }^{15} \mathrm{~N}$ ratios for Type $\mathrm{B} 1$ whales were significantly higher than those of $\mathrm{B} 2$ whales $\left({ }^{13} \mathrm{C}_{\mathrm{B} 1} x=-22.4, \mathrm{SD}=0.4 ;{ }^{13} \mathrm{C}_{\mathrm{B} 2}\right.$ $x=-22.8, \mathrm{SD}=0.3 . t$ test $p=0.007 ;{ }^{15} \mathrm{~N}_{\mathrm{B} 1} x=12.2, \mathrm{SD}=0.4$; ${ }^{15} \mathrm{~N}_{\mathrm{B} 2} x=11.3, \mathrm{SD}=0.2$. $t$ test $p<0.0001$ )

Analysis of mitochondrial genomes from a global dataset of killer whales placed Type B whales sampled around the Antarctic Peninsula into a monophyletic mitochondrial lineage, which is a sister clade to the Type $\mathrm{C}$ killer whale form found on the other (eastern) side of the Antarctic continent (Morin et al. 2015). However, Type B1 and B2 individuals sampled and sequenced to date do not share any mitochondrial haplotypes and appear to form two distinct subclades; they are also significantly differentiated at nuclear loci based on 91 nuclear single-nucleotide polymorphisms (Morin et al. 2015), and based on a whole genome comparison (Foote et al. in press). These results suggest that mating is not random among Type B killer whales, but rather that there is limited or no mating between Type B1 and Type B2.

This sympatric separation of B1 and B2 whales is similar to the reproductive isolation between sympatric killer whale ecotypes found in the NE Pacific (Morin et al. 2010; Parsons et al. 2013). However, genetic data suggest a relatively recent divergence of the B1 and B2 forms in Antarctica, following the release of habitat after the Last Glacial Maximum (see Morin et al. 2015; Foote et al. in press). Furthermore, in the NE Pacific, the dietary specializations between the ecotypes (e.g., mammal-eating "Transients" and the fish-eating "Residents") are well established (Ford et al. 1998; Herman et al. 2005), but further work is needed to elucidate the prey preferences and ecotypic distinction of B1 and B2 killer whales, and other Antarctic types (de Bruyn et al. 2013). Because the general Type B morphotype of killer whale has been documented around the Antarctic continent (Pitman and Ensor 2003), future work should also seek to identify the geographical extent of the B1/B2 variation to better parameterize models of trophic dynamics within Antarctica's changing marine ecosystems.

Acknowledgments Field efforts were supported by Lindblad Expeditions, National Geographic Society, and the BBC Natural History Unit. Jerome and Dion Poncet provided shipboard support; Stephanie Martin, Jason Kelley, and Lisa Kelley provided field assistance. Research was conducted under ACA Permit 2009-013, and MMPA Permits 774-1714 and 14097 issued to NOAA Southwest Fisheries Science Center. Phil Morin and Andy Foote provided useful comments on an earlier draft of this paper.

Open Access This article is distributed under the terms of the Creative Commons Attribution 4.0 International License (http://crea tivecommons.org/licenses/by/4.0/), which permits unrestricted use, distribution, and reproduction in any medium, provided you give appropriate credit to the original author(s) and the source, provide a link to the Creative Commons license, and indicate if changes were made.

\section{References}

Ainley D, Ballard G, Ackley S, Blight L, Eastman J, Emslie S, Lescroël A, Olmastroni S, Townsend S, Tynan C (2007) Paradigm lost, or is top-down forcing no longer significant in the Antarctic marine ecosystem? Antarct Sci 19:283-290

Ainley D, Ballard G, Blight L, Ackley S, Emslie S, Lescroël A, Olmastroni S, Townsend S, Tynan C, Wilson P (2010) Impacts of cetaceans on the structure of Southern Ocean food webs. Mar Mammal Sci 26:482-498

Branch TA, Butterworth DS (2001) Estimates of abundance south of $60 \&$ \#xB0;S for cetacean species sighted frequently on the 1978/79 to 1997/98 IWC/IDCR-SOWER sighting surveys. J Cetac Res Manage 3:251-270

de Bruyn PN, Tosh CA, Terauds A (2013) Killer whale ecotypes: is there a global model? Biol Rev 88:62-80

Durban JW, Parsons KM (2006) Laser-metrics of free-ranging killer whales. Mar Mammal Sci 22:735-743

Durban J, Ellifrit D, Dahlheim M, Waite J, Matkin C, Barrett-Lennard L, Ellis G, Pitman R, LeDuc R, Wade P (2010) Photographic mark-recapture analysis of clustered mammal-eating killer whales around the Aleutian Islands and Gulf of Alaska. Mar Biol 157:1591-1604

Foote AD, Vijay N, Ávila-Arcos MC, Baird RW, Durban JW, Fumagalli M, Gibbs RA, Hanson MB, Korneliussen TS, Martin MD, Robertson KM, Sousa VC, Vieira FG, Vinař T, Wade PR, Worley KC, Excorier L, Morin PA, Gilbert MTP, Wolf JBW (in press) Genome-culture coevolution promotes rapid divergence of killer whale ecotypes. Nat Commun

Ford JKB, Ellis GM, Barrett-Lennard LG, Morton AB, Palm RS, Balcomb KC (1998) Dietary specialization in two sympatric populations of killer whales (Orcinus orca) in coastal British Columbia and adjacent waters. Can J Zool 76:1456-1471

Herman DP, Burrows DG, Wade PR, Durban JW, LeDuc RG, Matkin CO, Barrett-Lennard LG, Krahn MM (2005) Feeding ecology of eastern North Pacific killer whales Orcinus orca from fatty acid, stable isotope, and organochlorine analyses of blubber biopsies. Mar Ecol Prog Ser 302:275-291 
Hooker SK, Iverson SJ, Ostrom P, Smith SC (2001) Diet of northern bottlenose whales inferred from fatty-acid and stable-isotope analyses of biopsy samples. Can J Zool 79:1442-1454

Krahn MM, Herman DP, Matkin CO, Durban JW, Barrett-Lennard LG, Burrows DG, Dahlheim ME, Black N, LeDuc RG, Wade PR (2007) Use of chemical tracers in assessing the diet and foraging regions of eastern North Pacific killer whales. Mar Environ Res 63:91-114

Morin PA, Archer FI, Foote AD, Vilstrup J, Allen EE, Wade P, Durban J, Parsons K, Pitman R, Li L, Bouffard P, Nielsen SCA, Rasmussen M, Willerslev E, Gilbert MTP, Harkins T (2010) Complete mitochondrial genome phylogeographic analysis of killer whales (Orcinus orca) indicates multiple species. Genome Res 20:908-916

Morin PA, Parsons KM, Archer FI, Ávila-Arcos MC, Barrett-Lennard LG, Dalla Rosa L, Duchêne S, Durban JW, Ellis GM, Ferguson SH (2015) Geographic and temporal dynamics of a global radiation and diversification in the killer whale. Mol Ecol 24:3964-3979

Parsons KM, Durban JW, Burdin AM, Burkanov VN, Pitman RL, Barlow J, Barrett-Lennard LG, LeDuc RG, Robertson KM, Matkin CO (2013) Geographic patterns of genetic differentiation among killer whales in the northern North Pacific. J Hered 104:737-754

Pitman RL (2011) Antarctic killer whales: top of the food chain at the bottom of the world. J Am Cetac Soc 40:39-45

Pitman RL, Durban JW (2010) Killer whale predation on penguins in Antarctica. Polar Biol 33:1589-1594

Pitman RL, Durban JW (2012) Cooperative hunting behavior, prey selectivity and prey handling by pack ice killer whales (Orcinus orca), Type B, in Antarctic Peninsula waters. Mar Mammal Sci 28:16-36

Pitman RL, Ensor P (2003) Three forms of killer whales (Orcinus orca) in Antarctic waters. J Cetac Res Manage 5:131-139

Pitman R, Perryman W, LeRoi D, Eilers E (2007) A dwarf form of killer whale in Antarctica. J Mammal 88:43-48

Pitman RL, Durban JW, Greenfelder M, Guinet C, Jorgensen M, Olson PA, Plana J, Tixier P, Towers JR (2011) Observations of a distinctive morphotype of killer whale (Orcinus orca), Type D, from subantarctic waters. Polar Biol 34:303-306

Stammerjohn SE, Martinson DG, Smith RC, Iannuzzi RA (2008) Sea ice in the western Antarctic Peninsula region: spatio-temporal variability from ecological and climate change perspectives. Deep Sea Res Part II 55:2041-2058 